\title{
Soil characteristic and soil iodine content of trans-polar territory of Pur-Taz interfluve of Western Siberia
}

\author{
B. A. Smolentsev ${ }^{*}$, G. A. Konarbaeva \\ Russian Academy of Sciences, Institute of Soil Science and Agrochemistry, Novosibirsk, Russia; \\ ${ }^{*}$ Corresponding Author: pedolog@ngs.ru
}

Received 7 November 2013; revised 7 December 2013; accepted 15 December 2013

Copyright (C) 2013 B. A. Smolentsev, G. A. Konarbaeva. This is an open access article distributed under the Creative Commons Attribution License, which permits unrestricted use, distribution, and reproduction in any medium, provided the original work is properly cited.

\begin{abstract}
Cryosols and Gleysols were described which form the basis of soil cover of drained spaces of trans-polar territory of Pur-Taz interfluve (Western Siberia, Russia). Their properties were characterized by a series of physical and chemical indices such as soil texture, field humidity, content of carbon and its group composition, $\mathrm{pH}$ values, exchange bases and hydrolytic acidity. The soils under study were named by World Reference Base, 2007. Conformity was considered to concern names of the studied soils with those of soil groups represented in Soil Atlas of the Northern Circumpolar Region, 2010. lodine content in the profile of soils was under consideration. It was correlated with some physical and chemical indices, and also environmental estimation of iodine content was given for soils of the north.
\end{abstract}

Keywords: Cryosols; Turbic Profiles; Iodine of Soils; Western Siberia

\section{INTRODUCTION}

The researches of the landscapes of the northern territories involve certain difficulties which cause financial costs for these researches, lack of advanced infrastructure as well as underdeveloped road network. The north of Western Siberia is no exception. Research history of Eurasian Cryosols was fully described by Goryachkin et al. in monograph [1]. As it evidenced by analysis of above-mentioned authors, the most part of the works devoted to soils of the north of Western Siberia concerns only north-taiga subbelt. At present time only one mono- graph available [2] is devoted to soils of forest tundra and tundra belts of Western Siberia. It is based on the results of proper researches of the authors. General characteristic of Cryosols of the north of Western Siberia was given by Karavaeva [1] on the basis of available data. Until now the fragmentary researches give a principal idea of soil cover of the north of Western Siberia. So, in literature there is no information on soil properties of trans-polar territory of Pur-Taz interfluve. Present paper deals with morphological description and physical and chemical characteristics of profiles of Cryozems and Gleyzems which form the basis of soil cover of trans-polar territory of Pur-Taz interfluve. The second aspect which was touched in this work consists in iodine content in the soils under study. Iodine is a trace element necessary for normal functioning of living organisms (human being and animals). Crucial role of halogen stimulates its study in natural objects.

Being engaged in detailed research of iodine in soils, waters and plants of the south of Western Siberia [3], the authors have considered that it is necessary to continue the researches in polar territories of Western Siberia as well, having begun with soils.

\section{MATERIALS AND METHODS}

\subsection{Natural Conditions}

The researches were conducted in forest tundra and tundra belts of Western Siberia within the limits of transpolar part of Pur-Taz interfluve. The territory under research is located in the area of glacial and fluvio-glacial depressed plains. Absolute heights fluctuate from 10 to $80 \mathrm{~m}$ above sea level.

The region of research is situated in subarctic climatic zone [4]. Mean annual air temperature amounts to $-9.2^{\circ} \mathrm{C}$. The winter moderately inclement and lasts eight 
months. Mean temperature in January amounts to $-26^{\circ} \mathrm{C}$. The thickness of snow cover in the basin of middle course of Taz River is $80-85 \mathrm{~cm}$. The duration of period with stable frosts is 200 days. Dates of transition of daily average temperatures through $0^{\circ} \mathrm{C}$ are registered later the 1 st of June. The return of colds and even snowfalls at the beginning of June are peculiar to spring. Monthly average temperature of May is $-2.1{ }^{\circ} \mathrm{C}$. The beginning of summer comes on 21-30st of June when daily average temperature of air becomes above $+10^{\circ} \mathrm{C}$. Average temperature of July is $16^{\circ} \mathrm{C}$. In September and October gradual fall of temperature and drizzles are observed. Soil freezing is marked already after the 20th of August. The winter comes in October when daily average temperatures pass through $-5^{\circ} \mathrm{C}$ and the steady snow cover is formed. Within a year the precipitation is as high as 220 $420 \mathrm{~mm}$, the most its part drops falls in summer and at the beginning of autumn.

The territory under research is situated in a zone noncontinuous distribution of permafrost, mainly marine glacial and marine quaternary deposits. Soil-forming rocks are represented by fluvio-glacial and lacustrine and alluvial stratified deposits. Rockiness is not found in rocks and soils.

The vegetation of typical tundra is presented by dwarf shrub-moss-lichen communities of drained territories. Plant communities with domination of Betula nana are spread on gentle slopes and on runoff dingles.

The basis of soil cover of the most broken part of the territory formed by light- and medium-textured rocks is provided by various types from the group of cryoturbic soils such as Gleyzems and Cryozems (by WRB Cryosols).

This article defines the characteristic of Typical Cryozems and Coarse Humus Cryozems and Cryometamorphic Cryoturbic Gleyzems.

Indexation of soil horizons and their name as well as the name of soils are given in the article according to Classification and Diagnostics of Soils of Russia [5]. After description each soil is determined by World reference base, 2006 (first update 2007) [6] using Soil Atlas of the Northern Circumpolar Region, 2010 [7].

\subsection{Methods}

Because of practical absence of data on physical chemical properties of the soils under study it has taken the determination of a large variety of soil parameters. In addition, all the samples were analyzed for total content of iodine and its water-soluble form.

Following procedures were used in analytical work. Carbon content was determined by method of WalkleyBlack [8], the soil texture by pipette method of [9], exchangeable $\mathrm{Ca}^{2+}$ and $\mathrm{Mg}^{2+}$ by percolation of the sample with ammonium acetate at $\mathrm{pH} 7, \mathrm{H}^{+}$and $\mathrm{Al}^{3+}$ by percola- tion of the sample with $1 \mathrm{M}$ solution of $\mathrm{KCl}[10,11]$, hydrolytic acidity by Kappen [12], amorphous iron compounds extraction with acid oxalate solution [13], total iodine content by kinetic thiocyanate and nitrite method in modification of Proskuryakova \& Nikitina [14]. Degree of base saturation was determined by formula $\mathrm{S} / \mathrm{T}$, where $\mathrm{S}$ is a sum of $\mathrm{Ca}^{2+}$ and $\mathrm{Mg}^{2+}, \mathrm{T}$ is a cation exchange capacity i.e. a sum of $\mathrm{S}$ and hydrolytic acidity. Calculation of results of soil analysis is done on the basis of oven-dry $\left(105^{\circ} \mathrm{C}\right)$. Period of sampling was from 20 to 25 of August 2009.

\section{RESULTS AND DISCUSSION}

\subsection{Morphological, Physical and Chemical Properties of Cryozems and Gleyzems}

Typical Cryozems are formed under conditions of hilly relief: they occupy tops and gentle slopes of the hills. Soil cover is spotty by its structure owing to abundant frost heaves that results in forming hillocky microrelief. Over-soil cover is presented by dwarf-lichen vegetation (Ledum palustre, Vaccinium uliginosum, Cladonia alpestris) with rare Betula nana and solitary Larix sibirica. In summer time soils thaw out up to the depth of $55-70 \mathrm{~cm}$. Morphological profile of Typical Cryozems becomes strongly deformed by cryogenic processes which become apparent as involutions, mixing soil material, disruption of soil horizons, organic matter intrusions and heave of horizons. It is practically impossible to distinguish soil column $10 \mathrm{~cm}$ wide with undisturbed genetic horizons.

In the upper part of profile of Typical Cryozems the litter and peaty horizon $(\mathrm{O})$ is formed $3-8 \mathrm{~cm}$ thick. It consists of weakly decomposed debris of shrubs, their roots and also moss. Loss on ignition of the sample from this horizon amounts to $25.5 \%$, this horizon is the most acid within the limits of the profile $\left(\mathrm{pHH}_{2} \mathrm{O}\right.$ is 3.5) and the least base-saturated ( $\mathrm{S} / \mathrm{T}$ is $7 \%$ ). Underlying horizons are situated in random way, both in vertical, and in horizontal direction. Sinuous narrow $(2-5 \mathrm{~cm})$ strips of grayish color and with increased content of organic matter $(0.77 \%)$ are found at different depth. These are buried fragments of humus horizon. This part of the profile is the moistest and strongly base-saturated ( $\mathrm{S} / \mathrm{T}$ is $14 \%$ ). Among mineral horizons these fragments have the largest values of exchangeable $\mathrm{H}^{+}$and $\mathrm{Al}^{3+}$, i.e. 4.48 and 4.26 $\mathrm{cmol}_{\mathrm{c}} \mathrm{kg}^{-1}$ respectively, and acid reaction at $\mathrm{pHH}_{2} \mathrm{O} 4.3$. Cryoturbic horizon $\mathrm{CR}_{3}$ which is not uniform by color is found below humus layers. It has general light yellowish brown hue with large quantity grey and ochre spots. This horizon is weakly acid $\left(\mathrm{pHH}_{2} \mathrm{O} 5.1\right)$, more base-saturated $(\mathrm{S} / \mathrm{T} 28 \%)$ as compared to upper thickness. Very pale brown horizon $\mathrm{CR}_{4}$ up to $10 \mathrm{~cm}$ thick is found below, it is bordered with yellowish red intercalations from above and from below. The upper part of yellowish red layer is 
$2-3 \mathrm{~cm}$ thick, the lower one $-\mathrm{CR}_{5}$ amounts to $12 \mathrm{~cm}$. The latter is formed on frozen mineral layer $\left(\mathrm{C}_{\perp}\right)$ where rare streaks of icy frost are found. Two lower horizons are the least acid in the profile; they are characterized by elevated content of exchange bases and the least value of hydrolytic acidity. Accordingly, degree of base saturation is the largest in these horizons.

Data on soil texture indicate to its certain heterogeneity throughout the profile (Figure 1(a)). Two upper horizons are lightly loamy by texture with predominance of fractions of sand and coarse silt. Downstream horizons are medium loamy with predominance of silty fractions. One can observe some increase in clay in the frozen horizon. It is impossible to catch regularities of distribution of texture fractions throughout the profile in connection with pedogenesis because the profile is strongly turbic. Original lithological heterogeneity of the profile seems to be in existence.

According to WRB the soil in question is classified as Turbic Cryosols (Hyperepidystric, Siltic).

Coarse Humus Cryozems are spread on narrow concave slopes towards runoff dingle under canopy of Betula nana, dwarf shrub and moss cover. They are formed on stratiform deposits not disturbed structure of which is well examined in the lower part of the profile. According to morphological signs and data on field moisture these soils are moister than Typical Cryozems. Dense thicket of Betula nana on the slopes of the runoff dingle favors to formation of thick snow cover which supplies the soil with moisture for a long time in spring and summer. The profile of coarse humus Cryosol is also cryoturbic but to a lesser extent as compared to typical analogues. Probably, snow cover and thick moss over-soil cover (up to 30 $\mathrm{cm}$ ) cause more stable temperature regime of soil profile. Mineral layer thaws out in summer up to the depth of 70 $-80 \mathrm{~cm}$.

Soil profile consists of following horizons: $\mathrm{O}$-litter and peaty, $\mathrm{AO}$ - coarse humus, Acr-humus cryoturbic, $\mathrm{CR}$-cryoturbic, $\mathrm{CRM}$ - cryometamorphic, $\mathrm{Cg} \perp$-frozen stratiform and gleyic rock.

Litter and peaty horizon is up to $30 \mathrm{~cm}$ thick. Its upper part (up to $10 \mathrm{~cm}$ thick) is as peaty tow (not dead part stalks of Polytrichum commune), the lower one is as a cobweb of roots of Betula nana, dwarf shrubs and dead stalks of green mosses. Coarse humus horizon $(4-7 \mathrm{~cm}$ thick) is a mixture of weakly decomposed plant debris and surface mineral layer. The value of loss on ignition of this horizon $(18.9 \%)$ bears witness to considerable content of organic matter in it. The horizon is characterized by high content of exchangeable $\mathrm{Al}^{3+}$ and $\mathrm{H}^{+}$especially, high hydrolytic acidity at low content of exchange bases. As a result is acid reaction and very low base saturation.

The pattern of humus cryoturbic horizon (Acr) is very not uniform. Against general brownish-gray background one can observe greenish or bluish gray and yellowish red brown and strongly wavy lines, semirings. Nearly black spots with coaly material are found. The thickness of humus horizon is about $15 \mathrm{~cm}$ and considerable carbon content (about $2 \%$ ) strongly differentiates these soils from all the soils of the territory under research. Soil reaction is acid because of high content of exchangeable $\mathrm{H}^{+}\left(9.26 \mathrm{cmol}_{\mathrm{c}} \mathrm{kg}^{-1}\right)$. The content of exchange bases is elevated in humus horizon, their sum amounts to 9.21 $\mathrm{cmol}_{\mathrm{c}} \mathrm{kg}^{-1}$, however, this value is less than that of hydrolytic acidity. Respectively, humus horizon is characterized by low degree of base saturation ( $44 \%-47 \%)$.

Throughout the entire humus layer $(\mathrm{AO}+\mathrm{Acr})$ a large quantity of amorphous forms of iron is observed, the most part of which seems to be combined with humus compounds. So, maximum values of iron correlate with the largest values of organic carbon. The examination of particles and aggregates under magnifying glass shows humus-ferrous films.

Cryoturbic horizon (CR) is very not uniform by structure and has respective pattern. Both upper humus fragments as well as fragments from the lower horizons are intermixed here. All of them form the pattern as involutions and narrow broken intercalations which are not well-ordered by direction and bends. General color background of this horizon is lighter as compared to that of humic, light-brown hue is predominant here. The content of organic matter sharply reduces up $0.27 \%$. The value of hydrolytic acidity drops off. $\mathrm{Ca}^{2+}$ and $\mathrm{Mg}^{2+}$ prevail in the composition of exchangeable cations. As a result, the reaction changes to weakly acid and degree of base saturation increases up to medium values $(62 \%)$.

Cryometamorphic horizon is more uniform throughout the entire profile of Coarse Humus Cryozems. Its upper border is vastly wavy; sometimes it merges with the lower one, thereby interrupting horizontal spreading of the horizon. The lower boundary is almost even. General background color of the horizon is grayish brown with abundant light gray powdering. This horizon has specific cryogenic ooid shape structure, akin to shot. In the lower part of the horizon the structure becomes platy. Carbon content continues to decrease. The proportion of exchangeable cations in absorbing complex increases that corresponds to elevated degree of base saturation. The reaction is left weakly acid, although the clear alkalinization is clearly observed by the value of $\mathrm{pH}$.

Soil-forming rock $(\mathrm{Cg} \perp)$ is as an alteration of the layers which differ in color and texture. The gleyed horizon of $3-5 \mathrm{~cm}$ in thickness is in the upper thawed out part of the profile. It is bluish gray and visually more heavytextured. In the lower frozen layers the streaks with ice are rare in occurrence. On the whole, the uncovered part of soil-forming rock has reaction close to neutral one and 
(a)

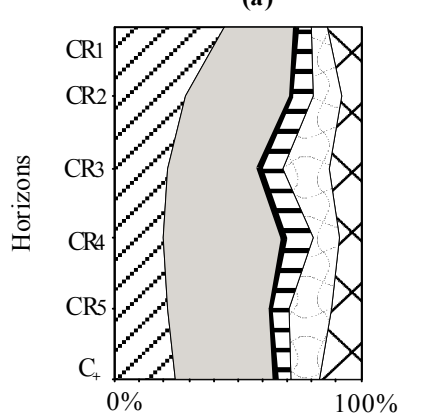

(b)

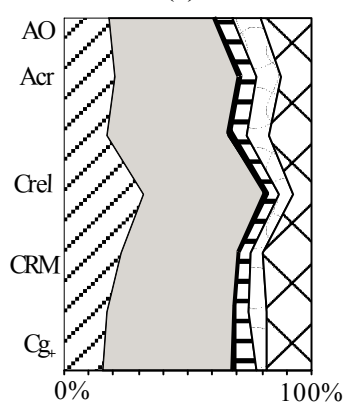

(c)

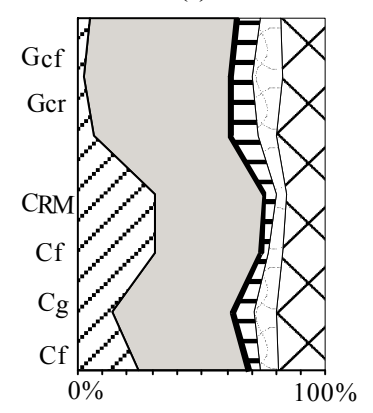

Size of particles, $\mathrm{mm}$

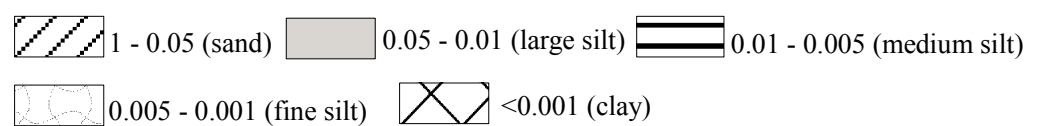

Figure 1. Texture of soils: (a) typical cryozems, (b) coarse humus cryozems, (c) cryometamorphic cryoturbic gleyzems.

elevated degree of base saturation, $\mathrm{Ca}^{+2}$ prevails among absorbed cations.

The texture of the horizons of Coarse Humus Cryozems evidences the eluvial and illuvial differentiation of its profile (Figure 1(b)). Cryoturbic horizon is the lightest by texture throughout the entire profile, it is loamy sandy. This horizon is the lightest by background color. Essential accumulation of clay is observed in downstream horizons. In addition, the color of cryometamorphic horizon is much darker than that of cryoturbic; and maximum silica powdering accounts for the transition part between these horizons.

According to WRB the soil in question is classified as Turbic Folic Cryosols (Ortoeutric, Siltic).

The third soil type widely displayed in soil cover of typical tundra of Pur-Taz interfluve is Cryometamorphic Cryoturbic Gleyzems. The soils of this type are spread on drained territories such as the tops and upper parts of the slopes of hill-like elevations with deeper (more than $1 \mathrm{~m}$ ) location of permafrost rocks.

Plant cover is represented by dwarf shrubs and lichens (Salix glauca, Cetraria islandica, Cladonia rangiferina).

The profile of Gleyzems is turbic but to a lesser degree as compared to that of Cryosols. Here a vertical column can be distinguished with complete set of type-diagnosticating horizons. The formula for profile is O-Gcf-GcrCRM-C (f, g). The litter and peaty horizon $\mathrm{O}$ is $5 \mathrm{~cm}$ thick. It consists of plant debris of various degree of decomposition interlaced with roots. Below there lies gley horizon Gcf. The central part of the horizon of $7-10 \mathrm{~cm}$ in thickness is bluish gray. From the top and from the bottom it is bordered by yellowish red intercalations of 1 $-3 \mathrm{~cm}$ thick. This horizon is the moistest in the upper part of the profile. It is characterized by weakly acid reaction and low base saturation. $\mathrm{H}^{+}$is prevailing among absorbed cations. Organic carbon content amounts to $0.5 \%$. The border of transition to the next horizon is wavy. Cryoturbic horizon (Gcr) is as a mixture of the fragments of different horizons such as humus, gley and cryometamorphic ones. Respectively, its color is not uniform, i.e. randomly spotty. The thickness of this horizon is on average about $20 \mathrm{~cm}$. One can observe in it the increased carbon content (up to $0.8 \%$ ) owing to turbic intercalations containing organic matter. Cryoturbic horizon is the most acid throughout the profile because of high content of $\mathrm{H}^{+}$and low values of $\mathrm{Ca}^{2+}$ and $\mathrm{Mg}^{2+}$. The degree of base saturation is low (S/T $25 \%-34 \%)$. Underlying horizon (CRM) coincides with the same horizon of Coarse Humus Cryozems by morphological and chemical properties. This horizon is the driest in the profile. The content of carbon and exchangeable $\mathrm{H}^{+}$is sharply reduced here. The proportion of $\mathrm{Ca}^{2+}$ increases notably in absorbing complex, it causes the increase in degree of base saturation and hydrogen potential. Strati-form soilforming rock $\mathrm{C}$ (f, g) is observed at the depth of $50-70$ $\mathrm{cm}$. The layers are thin $(1-3 \mathrm{~cm})$ and different by color. More commonly one can observe the alteration of the layers of yellowish red and light gray colors with light bluish gray hue. On the whole, soil-forming rock is moister than upper soil horizons. As for the rock, its light gleyed layers are moister than yellowish red ones. The analyzed layers of the rock have neutral hydrogen potential and elevated degree of base saturation. In the profile in question the frost was not observed up to the depth of $1.4 \mathrm{~m}$.

The texture of the horizons in Gleyzems is more uniform than in Cryozems (Figure 1(c)). Upper gley horizons and gleyed intercalations are medium loamy by texture with predominance of coarse silt fraction. Cryometamorphic horizon and yellowish red layers of the 
rock are light loamy by texture and contain considerable quantity of very fine sand.

According to WRB the soil in question is classified as Turbic Cryosols (Eutric, Reductaquic).

\subsection{Content and Distribution of lodine in Cryozems and Gleyzems}

The formation of soils in question under conditions of cold climate at low evaporability and under canopy of tundra cenosis has an influence not only on genesis of these soils but also, as a consequence, on content and distribution of iodine in them.

The content and regularities of iodine distribution in different soils testify that there is a set of factors responsible for accumulation and migration of iodine in soils [15]. Among these are organic matter content, soil texture, and reaction of soil medium, type of water regime as well as chemical properties of the halogen, as a such. Furthermore, the content of soil iodine is controlled by definite set of chemical properties of iodine and named factors. What this means is all the components of this set should have the same directionality. If they are differently directed, i.e. competitive, such a fact adversely affects accumulation of iodine and the process of its migration may become as a prevailing one.

The properties of the soils under research (Table 1) permit to suppose that iodine accumulation in them will be insignificant because any prerequisites for accumulation of its high concentrations are lacking. Principal factors responsible for iodine accumulation in soils are either weakly pronounced or directly opposite to process of accumulation by their nature. It should be also taken into consideration that iodine is a volatile, easily oxidizing and reducing element, and the most part of its salts is well soluble.

The content of organic carbon in the studied soils of tundra and forest tundra ranges from $0.1 \%$ to $2.1 \%$ that is classified as being low and extremely low. Humus formation is inhibited by prolonged stay of the soil in a frozen state. The same fact determines the course of transformation of organic debris and the nature of humus compounds. As for the composition of humus, fulvic acids are prevailing organic compounds in all the soils under research. The type of humus in all the horizons is humate-fulvate. The exception is humus horizon of Coarse Humus Cryozems where the type of humus is humate-fulvate; this fact is well correlated with increased content of absorbed bases in this horizon. The smaller the content of humus and more clearly pronounced its fulvate nature, the weaker its iodine-fixing capacity. The point is that when aromatic compounds interact with halogens the latter are combined most strongly while entering into benzene ring [16]. On evidence by Beyer [17] aromatic constituent of fulvic acids is much less than that of humic acids (39\%). Moreover, high content of carboxyl groups in fulvic acids $(8.2 \mathrm{mq} / \mathrm{g})$ as compared to humic acids $(3.6 \mathrm{mq} / \mathrm{g})$ [18] which are as electron-acceptor substituents, makes difficult the gaining of halogen. High content of oxygen in fulvic acids (up to $45 \%-50 \%)$ as compared to humic acids (32\% - 38\%) impedes their interaction with iodine because of possible electrostatic repulsion between negatively charged anions of oxygen and iodine [3].

Owing to the processes of sorption heavy loamy texture of soils saturated by clay fraction also favors to accumulation of iodine. The substitution of $\mathrm{OH}^{-}$ions of interlayer water of clay minerals, montmorillonite in particular, for $\mathrm{I}^{-}$is possible, as well as direct exchange of $\mathrm{I}^{-}$anions of the solution for easily accessible $\mathrm{OH}^{-}$anions of outer layers of minerals and as a result of slow process of diffusion of $\mathrm{I}^{-}$into lattice of the mineral. It is conveniently illustrated by example of the soils of Western Siberia. According to our data, maximum concentration of iodine $(10.0-18.7 \mathrm{mg} / \mathrm{kg})$ was pointed out in nitric horizon of five profiles where the content of clay fraction is approximately $39 \%-45 \%$. Therefore, it is natural that the value of correlation coefficient between these parameters amounted to $0.7-0.83$. In the soils of trans-polar territory the amount of clay fraction is not more than $20 \%$ that limits their capacity to fix halogen.

The reaction of soil medium influences on halogen behavior by dual manner. Alkaline reaction favors to accumulation of the element, as the reactions proceeding under such conditions with participation of iodine lead directly or indirectly to formation of more stable its anions such as $\mathrm{I}^{-}$and $\mathrm{IO}_{3}^{-}$. But under acid conditions the loss of halogen takes place at the expense of some chemical reactions. Under action of sunlight and acid conditions the oxidation of iodide-anion by atmospheric oxygen to free iodine takes place, which later on volatilizes from soil surface. The reaction is possible with participation of $\mathrm{BrO}^{-}$and $\mathrm{I}^{-}$anions with formation of free iodine when strongly acid medium is not required. The interaction between iodide and nitrite anions takes place in much the same manner although the probability of this reaction is not high because of low concentration of $\mathrm{NO}_{2}^{-}$anion. Nevertheless, $\mathrm{NO}_{2}^{-}$is found in soils and natural waters, it forms part of one of the links of nitrogen cycle. The reaction is specific for iodine, and so only it is lost. As the reaction of the soils under study is acid and strongly acid the contribution of hydrogen potential to accumulation of halogen is negative.

Periodically increased moisture of the profile of the soils of the northern territories does not favor to accumulation of iodine in view of good solubility of most its salts. According to researches [19] halogens are not sorbed under conditions of overmoistening. The saturation of soils with different easily soluble salts favors also 
Table 1. Soil analytical data.

\begin{tabular}{|c|c|c|c|c|c|c|c|c|c|c|c|}
\hline \multirow{3}{*}{ Horizons } & \multirow{3}{*}{$\begin{array}{c}\text { Depth of } \\
\text { sampling, sm }\end{array}$} & \multirow{3}{*}{$\mathrm{pHH}_{2} \mathrm{O}$} & \multicolumn{4}{|c|}{ Exchangeable cations } & \multirow{3}{*}{$\begin{array}{c}\text { Total } \\
\text { acidity }\end{array}$} & \multirow{3}{*}{$\begin{array}{c}\text { Base } \\
\text { saturation, } \\
\%\end{array}$} & \multirow{3}{*}{$\begin{array}{c}\text { Organic } \\
\text { C, } \%\end{array}$} & \multirow{3}{*}{$\begin{array}{l}\text { Iron by } \\
\text { Tamm, } \\
\text { mg/kg } \\
\text { soil }\end{array}$} & \multirow{3}{*}{$\begin{array}{c}\text { Field } \\
\text { moisture, } \\
\%\end{array}$} \\
\hline & & & $\mathbf{C a}^{2+}$ & $\mathbf{M g}^{2+}$ & $\mathbf{H}^{+}$ & $\mathbf{A l}^{3+}$ & & & & & \\
\hline & & & \multicolumn{4}{|c|}{$\mathrm{cmol}_{\mathrm{c}} \mathrm{kg}^{-1}$} & & & & & \\
\hline \multicolumn{12}{|c|}{ P.1. Typical Cryozems $\left(\mathrm{N}-67.272043^{\circ} ; \mathrm{E}-78.820460^{\circ}\right)$} \\
\hline $\mathrm{O}$ & $0-4$ & 3.5 & 1.73 & 0.61 & 13.79 & 6.58 & 30.19 & 7 & $25.5^{*}$ & 358.9 & \\
\hline $\mathrm{CR}_{1}$ & $4-11$ & 4.0 & 1.23 & 0.44 & 3.77 & 3.98 & 9.01 & 16 & 0.22 & 237.4 & 13.5 \\
\hline $\mathrm{CR}_{2}$ & $11-14$ & 4.3 & 1.27 & 0.36 & 4.48 & 4.26 & 10.24 & 14 & 0.47 & 264.6 & 16.8 \\
\hline $\mathrm{CR}_{3}$ & $15-25$ & 5.1 & 1.96 & 0.81 & 2.49 & 2.71 & 7.00 & 28 & 0.08 & 224.5 & 13.5 \\
\hline $\mathrm{CR}_{4}$ & $26-36$ & 5.1 & 2.36 & 0.87 & 0.40 & 0.70 & 3.33 & 49 & 0.06 & 211.6 & 14.9 \\
\hline $\mathrm{CR}_{5}$ & $40-50$ & 5.4 & 4.15 & 1.44 & 0.20 & 0.55 & 3.33 & 63 & 0.07 & 278.9 & 14.0 \\
\hline $\mathrm{C} \perp$ & $55-65$ & 5.7 & 4.76 & 1.87 & 0.08 & 0.10 & 2.27 & 74 & 0.06 & 291.7 & 18.0 \\
\hline \multicolumn{12}{|c|}{ P.2. Coarse Humus Cryozems $\left(\mathrm{N}-67.271667^{\circ} ; \mathrm{E}-78.827767^{\circ}\right)$} \\
\hline $\mathrm{AO}$ & $0-6$ & 4.4 & 4.33 & 3.25 & 23.67 & 3.62 & 27.3 & 22 & $18.9^{*}$ & 641.3 & \\
\hline \multirow[t]{2}{*}{ Acr } & $6-13$ & 4.9 & 5.14 & 4.07 & 9.26 & 0.85 & 11.99 & 43 & 2.12 & 671.6 & 30.5 \\
\hline & $13-20$ & 5.2 & 5.72 & 3.14 & 7.21 & 0.25 & 10.15 & 47 & 1.93 & 550.6 & 24.5 \\
\hline CRel & $20-28$ & 5.7 & 2.82 & 2.48 & 1.84 & 0.07 & 3.41 & 61 & 0.27 & 371.7 & 17.9 \\
\hline CRM & $35-45$ & 6.3 & 4.54 & 3.42 & 1.42 & -- & 2.25 & 78 & 0.20 & 343.0 & 17.9 \\
\hline $\mathrm{Cg}_{\perp}$ & $67-77$ & 6.6 & 7.70 & 2.35 & 0.61 & -- & 1.75 & 85 & 0.13 & 300.3 & 21.3 \\
\hline \multicolumn{12}{|c|}{ P.3. Cryometamorphic Cryoturbic Gleyzems $\left(\mathrm{N}-67.269816^{\circ} ; \mathrm{E}-78.808076^{\circ}\right)$} \\
\hline Gcf & $3-13$ & 5.2 & 2.74 & 1.87 & 4.27 & 0.84 & 6.21 & 43 & 0.50 & 492.9 & 21.7 \\
\hline \multirow[t]{2}{*}{ Gcr } & $14-24$ & 5.1 & 1.84 & 1.15 & 6.54 & 1.73 & 9.97 & 23 & 0.81 & 435.5 & 19.0 \\
\hline & $25-35$ & 5.3 & 2.74 & 1.23 & 6.31 & 1.09 & 8.22 & 33 & 0.71 & 450.0 & 16.5 \\
\hline CRM & $38-48$ & 6.2 & 5.11 & 1.62 & 0.81 & -- & 2.36 & 74 & 0.18 & 407.2 & 14.9 \\
\hline $\mathrm{Cf}$ & $65-70$ & 6.5 & 5.50 & 1.33 & 0.51 & -- & 2.01 & 77 & 0.17 & 393.1 & 18.2 \\
\hline $\mathrm{Cg}$ & $70-75$ & 6.7 & 6.05 & 1.72 & 0.31 & -- & 2.01 & 79 & 0.19 & 192.9 & 23.1 \\
\hline $\mathrm{Cf}$ & $130-140$ & 7.1 & 4.94 & 1.62 & 0.30 & -- & 1.31 & 83 & 0.11 & 300.2 & 20.4 \\
\hline
\end{tabular}

* Loss on ignition

to accumulation of iodine. It is well illustrated by example of saline soil of the south of Western Siberia where halogen content is maximum as compared to other soils of the region and amounts to $33 \mathrm{mg} / \mathrm{kg}$ [3]. It is evident from the literature that the sorption of iodine increases in the presence of different salts. On the basis of data on hydrogen potential one can point indirectly to absence of salinization in the profile of trans-polar soils and respectively to negative contribution of this factor to iodine accumulation.

In such a way, all the factors responsible for accumulation of iodine in the northern soils are practically lacking.

In our opinion, by iodine content the soils of tundra and forest tundra should be closer to taiga soils which we studied earlier [15]. Their main properties have much in common; for example, inconsiderable humus content, acid and strongly acid reaction, water regime. Therefore halogen content is similar in them. Iodine content in soils of the northern taiga (Podzols) varies from trace amounts to $1 \mathrm{mg} / \mathrm{kg}$. This element is lacking in horizons which are deeper $1 \mathrm{~m}$. Nevertheless, the dependence of iodine content on humus amount is still kept in these soils that has effect on value $r$ which varies from 0.55 to 0.61 .

The distribution of iodine differs in various soils in spite of identical low level of its content in them. Trace concentrations of halogen were found only in Gleyzems. This fact seems to be related to formation of Gleyzems under conditions of prolonged spring and summer overmoistening that leads to accumulation in organic matter of fractions such as fulvic acids and low-molecular acids which are the most active, mobile and less disposed to binding iodine.

As distinct from taiga soils, positive correlation between humus and iodine is lacking in the soils under study. Correlation coefficient amounts to -0.2 in Typical Cryozems, 0.11 in Cryometamorphic Cryoturbic Gleyzems, and only 0.74 in Coarse Humus Cryozems. The latter is determined by content of humus in the upper part of the profile and its gradual decrease downward the pro- 
file by analogy with soils of the south of Western Siberia.

In accordance with criteria by Kovalsky [20] concerning the content of total soil iodine (5.0 insufficient, 5.1 40.0 normal and more than $40 \mathrm{mg} / \mathrm{kg}$ - surplus) the studied soils of tundra and forest tundra are extremely poor in iodine.

Water-soluble iodine form cannot be present in soil in large quantity owing to active involving into biological cycle and descending migration. The change of its concentration occurs in wide range. This situation we connect with the lack of generally accepted methods for determination of this form. Different ratios soil: water and different time of their interaction are used at analysis. It leads to different results.

It is confirmed by data on water-soluble form of halogen (Table 2). The concentration of water-soluble form of soil iodine is usually estimated by criteria proposed by Pokatilov [21]. In accordance with them the content of water-soluble form of iodine (up to $0.011 \mathrm{mg} / \mathrm{kg}$ very low content, $0.011-0.03$ low, $0.031-0.05$ lowered, and
$0.051-0.1$ is optimum) should be recognized as being extremely low.

\section{CONCLUSIONS}

The profiles of Cryozems and Gleyzems are turbic by structure. The profile of Typical Cryozems where one cannot distinguish undisturbed pedon is turbic to a greater extent.

The soils are characterized by low and extremely low content of organic matter and predominance of fulvic acids in its composition, acid and strongly acid medium and base unsaturation. Strongly pronounced turbidity of soil profiles impedes the determination of development trend of pedogenesis and principal processes of soil formation in the soils under study.

Low content of organic carbon, predominance of fulvic acids in the composition of organic matter, acid medium, base unsaturation of soils of tundra and forest tundra determine extremely poor content of total iodine and very low content of its water-soluble form.

Table 2. Total content of iodine and concentration of its water-soluble form.

\begin{tabular}{|c|c|c|c|c|c|}
\hline \multirow{2}{*}{ Horizons } & \multirow{2}{*}{$\begin{array}{c}\text { Depth of sampling, } \\
\text { sm }\end{array}$} & \multirow{2}{*}{ Organic C, \% } & \multirow{2}{*}{$\mathbf{C}_{\mathbf{H A}} / \mathbf{C}_{\mathrm{FA}}$} & Total iodine & Water-soluble iodine \\
\hline & & & & \multicolumn{2}{|r|}{$\mathrm{mg} / \mathrm{kg}$} \\
\hline \multicolumn{6}{|c|}{ P.1. Typical Cryozems } \\
\hline $\mathrm{O}$ & $0-4$ & $25.5^{*}$ & 0.56 & 0.217 & 0.002 \\
\hline $\mathrm{CR}_{1}$ & $4-11$ & 0.22 & 0.48 & 0.447 & 0.004 \\
\hline $\mathrm{CR}_{2}$ & $11-14$ & 0.47 & 0.51 & 0.460 & 0.008 \\
\hline $\mathrm{CR}_{3}$ & $15-25$ & 0.08 & 0.42 & 0.233 & 0.0025 \\
\hline $\mathrm{CR}_{4}$ & $26-36$ & 0.06 & 0.37 & 0.140 & 0.0017 \\
\hline $\mathrm{CR}_{5}$ & $40-50$ & 0.07 & 0.33 & 0.200 & следы \\
\hline $\mathrm{C}_{\perp}$ & $55-65$ & 0.06 & 0.27 & 0.353 & 0.0027 \\
\hline \multicolumn{6}{|c|}{ P.2. Coarse Humus Cryozems } \\
\hline $\mathrm{AO}$ & $0-6$ & $18.9^{*}$ & 0.54 & 1.693 & 0.0017 \\
\hline \multirow[t]{2}{*}{ Acr } & $6-13$ & 2.12 & 0.71 & 0.570 & 0.0042 \\
\hline & $13-20$ & 1.93 & 0.74 & 1.200 & 0.0062 \\
\hline CRel & $20-28$ & 0.27 & 0.43 & 0.850 & 0.0059 \\
\hline CRM & $35-45$ & 0.20 & 0.33 & 0.700 & 0.0046 \\
\hline $\mathrm{Cg}_{\perp}$ & $67-77$ & 0.13 & 0.31 & 0.960 & 0.0025 \\
\hline \multicolumn{6}{|c|}{ P.3. Cryometamorphic Cryoturbic Gleyzems } \\
\hline Gcf & $3-13$ & 0.50 & 0.53 & 0.001 & 0.001 \\
\hline \multirow[t]{2}{*}{ Gcr } & $14-24$ & 0.81 & 0.49 & 0.560 & 0.015 \\
\hline & $25-35$ & 0.71 & 0.51 & 0.046 & 0.017 \\
\hline CRM & $38-48$ & 0.18 & 0.32 & 0.180 & 0.021 \\
\hline $\mathrm{Cf}$ & $65-70$ & 0.17 & 0.42 & 0.360 & 0.026 \\
\hline $\mathrm{Cg}$ & $70-75$ & 0.19 & 0.36 & 0.253 & 0.009 \\
\hline $\mathrm{Cf}$ & $130-140$ & 0.11 & 0.18 & 0.213 & 0.015 \\
\hline
\end{tabular}

*Loss on ignition 
Environmental situation concerning iodine content in soils of the north of Western Siberia should be estimated as being unfavorable.

\section{REFERENCES}

[1] Kimble, J.M. (2004) Cryosols: Permafrost-affected soils. Springer-Verlag, Berlin Heidelberg.

[2] Vasil'ievskaya, V.D., Ivanov, V.V. and Bogatyrev, L.G. (1986) Soils of the north of Western Siberia. Moscow.

[3] Konarbaeva, G.A. (2004) Halogens in soils of the south of Western Siberia. Novosibirsk.

[4] Sergeev, G.M. (1974) Agroclimatic resources of forest belt of West-Siberian plain. Irkutsk.

[5] Shishov, L.L., Tonkonogov, V.D., Lebedeva, I.I. and Gerasimova, M.I. (2004) Classification and diagnostics of soils of Russia. Smolensk.

[6] FAO (2007) World reference base for soils resources 2006. First update 2007. World Soils Resources Reports No. 103. FAO, Rome.

[7] (2010) Soil Atlas of the Northern Circumpolar Region. European Union.

[8] Nelson, D.W. and Sommers, L.E. Total carbon, organic carbon, and organic matter. In: Page, A.L., Ed., Methods of Soil Analysis. Part 2. Chemical and microbiological properties. 2nd Edition, Agronomy Series No. 9, ASA SSSA, Madison.

[9] Kachinski, N.A. (1958) Mechanical and microagregate composition of soil: Methods. AS USSR, Moscow.

[10] Dewis, J. and Freitas, F. (1970) Physical and chemical methods of soil and water analysis. FAO Soils Bulletin 10 . FAO, Rome.

[11] Chhabra, R., Pleysier, J.L. and Cremers, A. The meas- urement of the cation exchange capacity and exchangeable cations in soils: A new method. International Clay Conference, 439-449.

[12] Vorob'iova, L.A. (1998) Soil chemical analysis. Moscow.

[13] McKeaugue, J.A. and Day, J.H. (1966) Dithionite and oxalate extractable $\mathrm{Fe}$ and $\mathrm{Al}$ as aids in differentiating various classes of soils. Canadien Journal of Soil Science, 46, 13-22. http://dx.doi.org/10.4141/cjss66-003

[14] Proskuryakova, G.F. and Nikitina, O.N. (1976) Sort-cut variant of kinetic thiocyanate-nitrite method for determination of microquantities of iodine in biological objects. Agrochemistry, 7, 140-143.

[15] Konarbaeva, G.A. (2003) The total content and distribution of Iodine in the profile of some soils of Western Siberia. Agrochemistry, 8, 66-73.

[16] Karrer, P. (1959) Lehrbuch der organischer chemie. Georg Thieme Verlag, Stuttgart.

[17] Beyer, L. (1996) The chemical composition of soil organic matter in classical humic compound fractions and in bulk samples a review. Z. Pflanzenernahrung Bodenkunde, 6, 527-539. http://dx.doi.org/10.1002/jpln.1996.3581590603

[18] Schnitzer, M. (1977) Recent findings on the characterization of humic substances extracted from soils from differing climatic zones. Soil Organic Matter Studies. Proc. Symp. of Braunschweig, Vienna, 6-10 September 1976, 117-132.

[19] Ryoji, A., Hidenori, W. and Satoshi, M. (1990) Studies of specific adsorption of halogen in soils. 14th Int. Congr. Soil Sci., Kyoto, 12-18 August 1990, 287-288.

[20] Kovalsky, V.V. (1972) Biological role of iodine. Kolos, Moscow, 3-32.

[21] Pokatilov, Yu.G. (1993) Biogeochemistry of biosphere and medicobiological problems. Novosibirsk. 